\title{
LA SINGULARIDAD \\ DE LA MONARQUÍA SUECA \\ EN EL CONTEXTO EUROPEO: EL REY \\ COMO SÍMBOLO ESTÁTICO \\ DEL ESTADO
}

GÖRAN ROLLNERT LIERN 
SUMARIO

I. PLANTEAMIENTO DE LA CUESTIÓN. II. CARACTERIZACIÓN GENERAL DE LA MONARQUÍA SUECA EN EL INSTRUMENTO DE GOBIERNO DE 1975. III. LOS ANTECEDENTES INMEDIATOS: EL INSTRUMENTO DE GOBIERNO DE 1809. IV. LOS PODERES DEL REY Y EL COMPROMISO DE TUREKOV. V. DEL PARLAMENTARISMO NEGATIVO AL VOTO OBLIGATORIO DE INVESTIDURA EN LA REFORMA DE 2011. 


\title{
LA SINGULARIDAD \\ DE LA MONARQUÍA SUECA EN EL CONTEXTO EUROPEO: EL REY COMO SÍMBOLO ESTÁTICO DEL ESTADO ${ }^{1}$
}

\author{
GÖRAN ROLLNERT LIERN* \\ Profesor Titular de Derecho Constitucional \\ Universidad de Valencia
}

\section{PLANTEAMIENTO DE LA CUESTIÓN}

En el marco de las monarquías europeas, la configuración constitucional de la monarquía sueca contemporánea presenta singularidades que merecen atención. En términos generales, las monarquías europeas pueden calificarse como nominalmente constitucionales aunque materialmente parlamentarias. En este sentido, señalaba Jellinek en 1915 que la monarquía parlamentaria es «una

${ }^{1}$ El presente trabajo es resultado de la estancia de investigación realizada en julio de 2016 en la Facultad de Derecho de la Universidad de Estocolmo y es continuación de la ponencia «La monarquía sueca en perspectiva comparada» expuesta por el autor el 28 de julio de 2015 en el Encuentro «Monarquía, Constitución y democracia. España en perspectiva comparada», organizado por el Centro de Estudios Políticos y Constitucionales (CEPC) y el Real Instituto Elcano de Estudios Estratégicos e Internacionales bajo la dirección de Charles Powell en la Universidad Internacional Menéndez Pelayo (UIMP) de Santander (vídeos de la ponencia y la mesa redonda posterior disponibles en http://goo.gl/IcO14s y http://goo.gl/Qcf6ED). Si aquella ponencia se centró en el análisis comparativo de las monarquías sueca y española, en este artículo se tratan aquellos aspectos más específicos que caracterizan esta monarquía escandinava, prescindiendo del enfoque comparado con la monarquía española.

* Departamento de Derecho Constitucional, Ciencia Política y de la Administración. Facultad de Derecho Universidad de Valencia Campus de los Naranjos, s/n. 46071 Valencia (España). Email: Goran.Rollnert@gmail.com 
especie política de monarquía que descansa sobre las relaciones concretas de poder de los dos órganos inmediatos de Estado; esto es, se trata de una manera de ejercer el gobierno pero no es una forma de Estado estrictamente jurídica; es un compromiso impuesto por las relaciones políticas reales entre Corona y Parlamento. [...] La monarquía parlamentaria, como tal, no ha sido jurídicamente estructurada ${ }^{2} »$. Se trata, por tanto, de monarquías cuya distribución formal del poder responde a los principios propios de la monarquía constitucional ${ }^{3}$ pero cuyas prácticas políticas son las propias de una Jefatura del Estado de corte parlamentario por cuanto el Gobierno depende exclusivamente de la confianza parlamentaria ${ }^{4}$ y los actos del Rey deben contar inexcusablemente con el refrendo gubernamental, con el consiguiente efecto de trasladar a la esfera del Primer Ministro y de los Ministros la decisión subyacente al acto en cuestión.

Es este el caso de Bélgica, Holanda, Luxemburgo, Noruega, Dinamarca, Liechtenstein y Mónaco 5 . Dejando aparte las especificidades del modelo británico originario ${ }^{6}$, desde una perspectiva puramente nominalista solo los textos

2 Jellinek, G. (2000). Teoría General del Estado, Granada, Comares, 693 y 697.

3 En este texto se utiliza el término «monarquía constitucional» en sentido amplio, para designar la etapa de la evolución de la monarquía encuadrable entre la monarquía absoluta del Antiguo Régimen y la monarquía parlamentaria contemporánea, haciendo referencia a las monarquías supervivientes a las revoluciones liberales en las que el Rey se convirtió en un órgano constitucional que ejercía el poder ejecutivo y compartía el poder legislativo con el Parlamento [DE Vergottini, G. (1983). Derecho Constitucional Comparado, Madrid, Espasa-Calpe, 707]. Aunque no existe unanimidad doctrinal al respecto, cabe diferenciar una fase previa, la «monarquía limitada» basada en el principio monárquico en la que el Rey era el titular de la soberanía que otorgaba voluntaria y graciosamente una Constitución (en realidad, una Carta otorgada como la francesa de 1814) en la que autolimitaba sus poderes y reconocía derechos a sus súbditos, y, por otra parte, la monarquía constitucional en sentido estricto que sería la monarquía orleanista, la Monarquía de Julio de 1830, de Luis Felipe de Orleans, en la que se introdujo el parlamentarismo dualista al necesitar el Gobierno la doble confianza (del Rey y del Parlamento) para mantenerse en el cargo. Sobre la monarquía limitada y la monarquía constitucional véase la amplia exposición de Pérez de Armiñán y de la Serna [Fernández-Fontecha Torres, M. y Pérez de Armiñan y de la SERna, A. (1987). La Monarquía y la Constitución, Madrid, Civitas, 19-76] y, más sintéticamente, Torres Del Moral, A. (1995). «Introducción: monarquía, democracia y opinión pública», en Torres del Moral, A. y Gómez Sánchez, Y., Estudios sobre la monarquía, UNED, Madrid, 13-14.

4 Stepan, A., Linz, J. J. y Minoves, J. F. (2014). «Democratic Parliamentary Monarchies», Journal of Democracy, vol. 25, n. ${ }^{\circ} 2,36$.

$5 \mathrm{Vid}$. al respecto un estudio comparado de estas monarquías en Rollnert Liern, G. (2007). «Las Coronas europeas y sus funciones representativas», en Rollnert Liern, G. (dir.), Las Monarquías Europeas en el siglo XXI, Madrid, Sanz y Torres, 38-48.

6 Vid. Bogdanor, V. (1991). «The constitutional monarchy in the United Kingdom», Res publica, v. 33, n. ${ }^{\circ}$ 1, 7-23. En el contexto británico, Bogdanor utiliza la expresión «monarquía 
constitucionales de Dinamarca, Liechtenstein y Mónaco recogen expresamente la fórmula «monarquía constitucional» para definir su forma de gobierno. Por su parte, la Constitución de Noruega habla de «monarquía limitada ${ }^{7}$ » sin que ello implique una vigencia efectiva del principio monárquico ${ }^{8}$ —la titularidad regia de la soberanía - ni que el Rey noruego tenga una autoridad y un ámbito de poder efectivo superior al del resto de monarcas europeos. El principio parlamentario, no obstante, está constitucionalizado en Liechtenstein y Luxemburgo e, implícitamente, en Dinamarca.

Sin embargo, frente a esta situación ampliamente mayoritaria, hay dos monarquías europeas que son monarquías parlamentarias constitucionalizadas como tales por tratarse de Estados monárquicos en cuyos textos constitucionales se ha producido una recepción expresa de la monarquía parlamentaria como último estadio de la evolución de las monarquías europeas, evolución producida en buena parte mediante reglas convencionales y al margen de la Constitución escrita. Es el caso de Suecia y España, sin perjuicio de que en la respectiva regulación constitucional de la institución regia existan diferencias significativas a las que se hará alguna referencia posteriormente.

De los dos textos constitucionales, el sueco de 1975 y el español de 1978, pueden destacarse como elementos comunes la proclamación de la soberanía popular (arts. 1.2 CE y 1, Cap. 1 del Instrumento de Gobierno sueco, en adelan-

constitucional» en el mismo sentido en el que se usa habitualmente la fórmula «monarquía parlamentaria» en el ámbito continental [BogDANOR (1995). The Monarchy and the Constitution, Oxford, Clarendon Press, 1 y 2].

7 Suele citarse como paradigmático de la monarquía limitada el Preámbulo de la Carta francesa de 1814 del que se extractan los siguientes párrafos como los más significativos: «se ha solicitado una Carta constitucional debido al estado actual del Reino; la hemos prometido y la publicamos. Hemos considerado que, aunque toda la autoridad ha residido en Francia en la persona del Rey, nuestros predecesores no han dudado en modificar su ejercicio según la diferencia de los tiempos, [...]. Hemos acordado voluntariamente y por el libre ejercicio de nuestra autoridad real y acordamos, conceder y otorgar a nuestros súbditos tanto para Nos como para nuestros sucesores y para siempre, de la siguiente Carta Constitucional».

8 Para Menéndez Rexach, la formulación clásica del principio monárquico se contiene en al artículo II, 1. ${ }^{\circ}$ de la Constitución bávara de 1818 («el Rey es el Jefe del Estado, reúne en sí todos los derechos del poder del Estado y los ejerce conforme a las determinaciones acordadas por él y fijadas en el presente documento constitucional») y fue posteriormente extendido a toda la Federación alemana por el artículo 57 del Acta final de Viena de 1820. Vid. Menéndez ReXacH, A. (1979). La Jefatura del Estado en el Derecho Público Español, Madrid, Instituto Nacional de Administración Pública, 68; y Heun, W. (2000). «El principio monárquico y el constitucionalismo alemán del siglo XıX». Fundamentos, n. ${ }^{2}$. Recuperado el 16.01.2017 de http://goo.gl/79qq4u. 
te $\mathrm{IG}^{9}$ ) y que ambos se refieren expresamente al Rey como «Jefe del Estado» (arts. 56.1 CE y 1, Cap. 5 IG). No obstante, aunque el IG proclama expresamente una forma de gobierno «representativa y parlamentaria» (art. 1 del Cap. 1), solo la Constitución española acoge expresamente la fórmula «monarquía parlamentaria» como «forma política del Estado» (art. 1.3 CE) y atribuye literalmente al monarca la condición de, en cuanto Jefe del Estado, «símbolo de su unidad y permanencia ${ }^{10} \gg$ (art. 56.1 CE); como se expondrá, ambos monarcas representan simbólicamente la unidad del Estado pero la diferencia entre la configuración de la Jefatura del Estado en los dos países radica en la forma en que esa simbolización ${ }^{11}$ se lleva a cabo y, especialmente, en que el soberano sueco se halla prácticamente desprovisto de las funciones de representación jurídica del Estado atribuidas constitucionalmente al monarca español.

Sobre estos presupuestos, se analiza a continuación esa significativa carencia de competencias que individualiza la posición del Jefe de Estado sueco respecto de los restantes monarcas europeos. Se parte de una visión panorámica general de la monarquía sueca, se aborda a continuación la evolución de la institución en Suecia a partir del anterior Instrumento de Gobierno de 1809 para tratar después de la discusión sobre los poderes del Rey durante la tramitación parlamentaria de la nueva Constitución de 1975, finalizando con la llamativa ausencia del soberano en el proceso de formación del gobierno y la incidencia de la

9 Todas las referencias a los diversos textos que integran la Constitución de Suecia deben entenderse hechas a la versión inglesa publicada por el Parlamento sueco: THE SWEDISH RIKSDAG. (2012). The Constitution of Sweden. The Fundamental Laws and the Riksdag Act, Stockholm, Sveriges Riksdag. Recuperado el 16.01.2017 de https://goo.gl/cAKB2E.

${ }_{10}$ Hasta la reforma de la Constitución luxemburguesa en 1998, la Constitución española de 1978 era también el único texto constitucional entre los europeos, que definía al Rey como «símbolo» de la unidad y permanencia del Estado. Tras la reforma de 12 de enero de 1998 el artículo 33 de la Constitución de Luxemburgo declara que «el Gran Duque es el Jefe del Estado, símbolo de su unidad y garante de la independencia nacional». Al margen del marco europeo, la Constitución japonesa de 3 de noviembre de 1946, que entró en vigor el 3 de mayo de 1947, define al Emperador como «símbolo del Estado y de la unidad del pueblo» (art. 1). Vid. al respecto RodríGUez Artacho, S. (2001). «La Monarquía en Japón: el marco jurídico en torno a la figura del Tennô», en Torres del Moral, A. (dir.), Monarquía y Constitución (I), Madrid, Colex, 117-122.

11 Las diferencias concretas entre las funciones simbólicas de ambos monarcas se analizan con detalle en Rollnert Liern, G. (2007), 48-53. Sobre la función simbólica del Rey de España, Torres del Moral, A. (2004). «Concepción pansimbolista de la monarquía parlamentaria». Corts: Anuario De Derecho Parlamentario, núm. 15, 195-204; RollnerT Liern, G. (2006). «La función simbólica», en Gómez SÁnCHeZ, Y. (coord.), XXV años de Monarquía Parlamentaria, Madrid, Sanz y Torres, 161-189; y, más extensamente, RollnerT Liern, G. (2002). La Jefatura del Estado: símbolo e integración política en la Constitución vigente, Valencia, Colección Ideas y Políticas Constitucionales (CIPC), Mínim Edicions, https://goo.gl/GtoKJP. 
reforma constitucional de 2011 en la regulación del voto de investidura del Primer Ministro.

\section{CARACTERIZACIÓN GENERAL DE LA MONARQUÍA SUECA}

La Constitución sueca es lo que llaman los comparatistas italianos una Constitución pluritextual ${ }^{12}$ integrada por cuatro Leyes Fundamentales del Reino (art. 3, Cap. 1 IG): el Instrumento de Gobierno (Regeringsformen, RF) de 1975, que reemplazó al anterior de 1809; la Ley de Sucesión (Succesionsordningen) de 1809, la Ley de Libertad de Prensa (Tryckfribetsförordningen) de 1810 y la Ley Fundamental sobre la Libertad de Expresión (Yttrandefribetsgrundlagen) de 1991.

De estas cuatro leyes fundamentales, la que interesa en particular es el Instrumento de Gobierno, también conocido como la Ley de la Constitución o la Ley Fundamental sobre la Forma de Gobierno, que establece que el Rey o la Reina que ocupe el trono de Suecia de acuerdo con la Ley de Sucesión será el «Jefe del Estado» (arts. 5, Cap. 1 y 1, Cap. 5 IG) y proclama expresamente una forma de gobierno «representativa y parlamentaria» (art. 1, Cap. 1).

El primer rasgo a mencionar es que el Rey no ostenta la titularidad del poder ejecutivo atribuyéndose este al Gobierno responsable políticamente ante el Riksdag o Parlamento (art. 6, Cap. I) que puede aprobar por mayoría absoluta una moción de censura (declaración de desconfianza) contra el Primer Ministro o individualmente contra cualquier ministro (arts. 7, Cap. 6 y 4, Cap. 13), pudiendo el Gobierno convocar nuevas elecciones extraordinarias en la semana siguiente a la aprobación de una moción de censura (art. 7, Cap. 6). No está regulada la cuestión de confianza pero se ha hecho uso de ella en alguna ocasión ${ }^{13}$.

Pese a que el Rey de Suecia no es titular del poder ejecutivo, tiene una muy reducida participación en algunos de sus actos, nimia si se compara con las monarquías nominalmente constitucionales o incluso con la monarquía española, y que parece tener su fundamento en una mínima cortesía o consideración institucional hacia la máxima figura del Estado en el orden protocolario. Así, aunque no preside ordinariamente las reuniones del Gobierno, el Primer Ministro debe mantenerle al corriente de los asuntos del Reino, reuniéndose el Gobier-

12 Durantr, F. (2012). «Evoluzioni del costituzionalismo svedese». Federalismi.it, n. ${ }^{\circ}$ 3, 1-2. Recuperado el 16.01.2017 de http://goo.gl/86xeYh.

13 Holmberg, E. y STJernquist, N. (1995). «Introduction», The Constitution of Sweden, Stockholm, The Swedish Riksdag, 46-47. 
no ${ }^{14}$ bajo su presidencia «cuando sea necesario» (art. 3, Cap. 5 IG) y, por otra parte, la constitución del nuevo Gabinete tiene lugar en su presencia en una reunión especial del Consejo (art. 6, Cap. 6 IG), reuniéndose en tales casos el Gobierno como «Consejo de Estado ${ }^{15}{ }$; sin duda, lo más definitorio de la posición constitucional del monarca sueco es que no tiene atribuidas ni la propuesta ni el nombramiento del Primer Ministro, que se efectúa por el Presidente del Riksdag (arts. 3-5, Cap. 6), y se limita, por tanto, a estar presente en esa reunión especial del Consejo en la que se constituye el nuevo Gobierno.

Por lo que se refiere al poder legislativo, se atribuye al Parlamento (Riksdag) como supremo órgano representativo del pueblo sueco (art. 4, Cap. I) y la intervención del soberano tiene todavía un carácter más ceremonial, si cabe. No existe la sanción de las leyes y es el Gobierno el encargado de promulgarlas y publicarlas (art. 19, Cap. 8). En virtud de la Ley del Riksdag ${ }^{16}$ (Riksdagordningen), el monarca abre solemnemente las sesiones anuales del Parlamento por invitación de su Presidente, pronuncia el discurso del Trono (Trontalet) con el programa del Gobierno $^{17}$ y tiene también la facultad de hacer declaraciones ante él por su propia iniciativa (arts. 4, Cap. 1 y 10, Cap. 12). Sin embargo, es el Gobierno y

14 A estos efectos informativos, se celebran dos o tres reuniones anuales del Gobierno con el Rey para las que aún se utiliza la antigua expresión «el Rey en Consejo» [LARsson, T. (1997). «Sweden: The new Constitution - An old practice adjusted», en Blondel, J. y Müller-RomMEL, F. (eds.), Cabinets in Western Europe, 2. ${ }^{a}$ ed., New York, St. Martin's Press, 233; y Nyman, O. (1981). Some Basic Features of Swedish Constitutional Law, en STrömHOLM S. (ed.), An Introduction to Swedish Law, Stockholm, Norstedt, 61-62]. Parece dudar, sin embargo, de la celebración de dichas reuniones — «very rarely, if ever»- Nergelius, J. (2015). Constitutional Law in Sweden, 2. ed., Wolters Kluwer Law \& Business, 41-42.

15 Cabe señalar que el actual Instrumento de Gobierno distingue entre las reuniones ordinarias del Gobierno y las reuniones del mismo presididas por el Rey que denomina «Consejo de Estado» como trasunto de la antigua expresión «el Rey en Consejo» que, al igual que las últimas funciones residuales provenientes de la Constitución de 1809, desapareció del texto constitucional en la reforma de 1975 y que hacía referencia a las reuniones formales del Gabinete en las que el Rey y sus Ministros tomaban conjuntamente las decisiones de gobierno [HANCOCK M. D. (1998). «Sweden», Politics in Western Europe, 2. ${ }^{\text {e }}$ ed., Chatham, New Jersey, Chatham House Publishers, 452]. Sobre la posición del Rey de Suecia en la Constitución sueca de 1809 antes de la reforma de

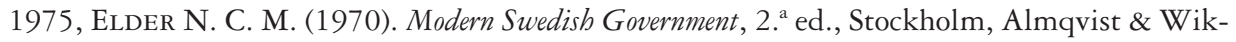
sell, 113-122.

16 Hasta 1975 la Ley del Riksdag (Riksdagsordningen), equiparable al reglamento parlamentario, fue una de las Leyes Fundamentales del Reino que integraban la Constitución de Suecia; desde la reforma de 1975 ocupa en la jerarquía normativa una posición intermedia entre las Leyes Fundamentales y las leyes ordinarias [art. 16, Cap. 8 IG y Hombelrg y STJERnQUIST (1995), 33-34].

17 Andrén, N. (1968). Modern Swedish Government, 2a ed., Stockholm, Almqvist \& Wiksell. 
no el Rey quien puede disolver el Parlamento ${ }^{18}$ y convocar unas elecciones extraordinarias (art. 11, Cap. 3).

En el ámbito de las relaciones internacionales, el Rey de Suecia preside el Comité de Asuntos Extranjeros ${ }^{19}$ (Utrikesniimnden) del Riksdag (art. 12, Cap. 10) pero carece constitucionalmente de competencias para la ratificación de tratados internacionales, la acreditación de representantes diplomáticos y la declaración de la guerra y de la paz. La única mención al Rey a este respecto es para establecer su obligación de consultar al Primer Ministro antes de viajar al extranjero (art. 3, Cap. 5). Sin embargo, hasta el año 2003 los tratados internacionales los ratificaba el Ministro de Asuntos Exteriores «en el nombre de su Majestad el Rey de Suecia» que figuraba como la Alta Parte Contratante, aunque el Rey no tuviera una atribución constitucional formal; a partir del año 2003 cambió la prácti$\mathrm{ca}^{20}$ y empezó a ratificarlos el Ministro de Asuntos Exteriores «en nombre del Gobierno de Suecia» que es la Alta Parte Contratante desde esa fecha, siendo el único caso en la Unión Europea en el que no es parte contratante el Jefe del Estado. Además, por convención constitucional y por aplicación de las reglas del Derecho Internacional, se le considera supremo representante de Suecia en las relaciones internacionales y, como tal, recibe las credenciales de los embajadores extranjeros en una audiencia en el Palacio Real, firma las credenciales de los embajadores suecos, realiza viajes de Estado y actúa como anfitrión en las visitas de los Jefes de Estado extranjeros ${ }^{21}$.

En coherencia con el principio de soberanía popular, el monarca carece de participación alguna en el proceso de reforma constitucional (arts. 14-16, Cap. 8 IG) y es la única monarquía en la que la justicia no se administra en nombre del

18 Duranti, F. (2009). Gli ordinamenti costituzionali nordici. Profili di diritto pubblico comparato, Torino, Giappichelli, 95, nota 80.

19 Para Nergelius, esta importante atribución resulta algo sorprendente en el contexto de la reforma constitucional de 1975 y encuentra su justificación en las previsibles dificultades del Primer Ministro en disponer de tiempo para informar regularmente al Jefe del Estado y en la necesidad de que el monarca esté informado sobre la situación internacional antes de sus viajes de Estado, haciéndose eco de las críticas que recibió el Gobierno por no informar al Rey a su debido tiempo después del tsunami de diciembre de 2004 en el que fallecieron 543 ciudadanos suecos [NERGELIUS (2015), 41-42]

20 Información proporcionada al autor por N. Vabi que tuvo a bien proporcionarle (y traducirle) las notas que utilizó para elaborar el trabajo de 2003 al que se hace posterior referencia.

21 Hombelrg y Stjernquist (1995), 30. Señala Lagerqvist que el residuo de poder que le queda al monarca sueco en las relaciones exteriores se debe a que para alterar su posición habría que renegociar los tratados con todos los Estados parte [LAGERQVIST VELOz RocA, A. (2000). «El concepto de soberanía en conformidad con el Derecho sueco», en Ramírez Necochea, M.; Fuentes Torrijo, X., Rodríguez Elizondo, J. y Lagerqvist Veloz Roca, A., La soberanía en el mundo actual, Santiago de Chile, LOM Ediciones, 123]. 
Rey $^{22}$ quien tampoco ejerce el derecho de gracia que se atribuye constitucionalmente al Gobierno ${ }^{23}$ (art. 9, Cap. 12).

Así pues, el soberano sueco apenas ejerce funciones en relación con los poderes del Estado y las escasas que tiene atribuidas son de naturaleza ceremonial ${ }^{24}$, con la única excepción de presidir el Consejo de Ministros en los casos mencionados. Su función es estrictamente simbólica ${ }^{25}$. Es cierto que, a diferencia del texto español, no tiene expresamente atribuida la condición de símbolo en la Constitución pero esta va implícitamente unida a su posición de Jefe del Estado de tal manera que es consustancial a la institución, con independencia de su reconocimiento constitucional. Sin embargo, hay otra diferencia de mayor fuste con la posición simbólica del monarca español: si este es un símbolo dinámico que renueva continuamente su carga simbólica mediante el ejercicio de sus potestades constitucionales, es decir, mediante actos de representación jurídica o de arbitraje y moderación ${ }^{26}$, el Rey de Suecia, al estar desprovisto de compe-

22 Bajo la vigencia del anterior Instrumento de Gobierno de 1809 el Tribunal Supremo y el Tribunal Supremo Administrativo actuaban en nombre del Rey [ANDRÉN (1968), 113] y hasta 1909 el Rey tenía dos votos en el Tribunal Supremo [Petersson, O. (2009), The Swedish 1809 Constitution. Paper prepared for Conference on Contested Sovereignties Constitutional Arrangements and their Relevance for Democracy: European and Middle Eastern Perspectives, Swedish Research Institute in Istanbul Ayvalik 28-31 May, 2009, Stockholm, The Swedish Centre for Business and Policy Studies, SNS, 7. Recuperado el 16.01.2017 de http://goo.gl/w9nbrh; y Holmberg y STJERnQuist (1995), 13 ].

23 VABI, N. (2003). «Stastchefens offentligrättsliga status» (El estatuto del Jefe del Estado en el Derecho Público), Förvaltningsrättslig tidskrift, n. ${ }^{\circ}$ 66, 127 y 137. El autor agradece a N. Vabi su deferencia de traducirle las tesis fundamentales de su artículo.

24 «Ceremonial» es el término más utilizado entre la doctrina para definir la posición del Rey de Suecia [Nyman (1981), 54; Hancock (1988), 446 y 452; LARSSON, T [(1991). «Sweden, the Crown of the State», Res publica, vol. 33, 1991/1, 50; (1997), 225]; BErGman, T. (1992). «Multiple Goals and Constitutional Design: How the Swedish King Lost His Formal Powers», Statsvetenskaplig tidskrift, n. ${ }^{\circ}$ 95, 214; HolmBERG y STJERNQUIST (1995), 30; VABI (2003), 140; y Petersson (2009), 19] y lo mismo hace el propio sitio web oficial de la Casa Real (http://goo.gl/ tkYR83 a fecha 16.01.2017). En este sentido, se cita también como ejemplo de su rol ceremonial, además de la apertura anual del Riksdag, su participación en la ceremonia de concesión de los premios Nobel [HANCOCK (1988), 452-453). Larsson califica la posición de la Corona en el Estado sueco como «puramente ornamental» [LARSSON (1991), 60].

25 VABI (2003), 127, 138 y 156-157 y STERZEL, F. (1997). «Statschefen ställning» (La posición del Jefe del Estado), Festskrift till Stig Strömbolm, Uppsala, Iustus, 808 y 819 (traducido por Nils-Göran Rollnert, q.e.p.d.).

26 Rollnert Liern, G. (2005). El arbitraje y moderación regios en la Constitución española de 1978, Valencia, Servicio de Publicaciones de la Universidad de Valencia, 165-184 y 192-194. Cabe señalar a este respecto que una de las bazas argumentales de la posición doctrinal minoritaria que defiende una interpretación extensiva de las funciones arbitral y moderadora del Rey de España (fundamentalmente M. Herrero Rodríguez de Miñón y M. Fernández-Fontecha Torres) es 
tencias sustantivas y de potestades de acción, se limita, en la mayoría de los casos, a simbolizar ${ }^{27}$ pasivamente, con su mera presencia estática, la unidad del Estado sueco. En este sentido resultan muy expresivas las cláusulas constitucionales que obligan al Rey a acompañar al Gobierno en caso de guerra, entendiéndose que se encuentra impedido para ejercer sus obligaciones como Jefe de Estado si se encontrara en territorio ocupado o separado del Gobierno (art. 10, Cap. 15); la significación simbólica es evidente: el Rey, en cuanto encarnación simbólica del Estado, no puede hallarse físicamente en lugar distinto al Gabinete porque ello supondría visibilizar una separación entre el Gobierno legítimo y el Estado en una situación de conflicto bélico con una potencia extranjera.

En definitiva, la vigente Constitución sueca de 1 de enero de 1975, pese a ser cronológicamente anterior a la española, ha llevado a su máxima expresión la desvinculación de la Jefatura del Estado respecto de los poderes estatales ${ }^{28}$ configurando así un modelo propio de racionalización de la monarquía parlamentaria en el texto constitucional escrito. Esta reducción al mínimo de las funciones del monarca en la Constitución sueca ha dado lugar a una opinión doctrinal que considera que la monarquía sueca, junto con la japonesa, constituyen el último estadio en la evolución de la monarquía, llegando algunos incluso a afirmar que se trataría de un nuevo tipo o modelo distinto al prototipo europeo de la monarquía parlamentaria ${ }^{29}$ al que denominan «Monarquía simbólica e institucionalmente representativa ${ }^{30} » 0$ «Monarquía democrático-parlamentaria ${ }^{31} »$.

el recurso a los trabajos parlamentarios de la Constitución de 1978 para alegar que los constituyentes rechazaron expresamente el modelo sueco de monarquía que reduce al Jefe del Estado a la estricta condición de símbolo para afirmar, a contrario sensu, la voluntad constituyente de dotar al monarca español de un papel arbitral y moderador con un contenido real y efectivo no reducible a las estrictas competencias del artículo 62 CE [ROLLNERT LIERN (2005), $40-46$ y 141-142].

${ }^{27}$ LARSSON (1991), 50.

${ }^{28}$ Larsson (1991), 49-50 y 60; y Porras Ramírez, J. M (1995). Principio democrático y función regia en la constitución normativa, Madrid, Tecnos, 120.

${ }^{29}$ Contrariamente, para Andrén no existen diferencias sustanciales entre la monarquía sueca y las otras dos monarquías escandinavas (Dinamarca y Noruega), siendo las tres monarquías parlamentarias en las que el Jefe del Estado ocupa idéntica posición [ANDRÉn (1968), 187].

30 García Canales, M. (2001). «Las monarquías parlamentarias europeas», en Torres Del Moral, A. (dir.), Monarquía y Constitución (I), Madrid, Colex, (2001), 91. En un sentido similar, Häberle considera que el Estado constitucional monárquico sueco puede caracterizarse como «puramente representativo» al quedar completamente excluido el Rey de toda participación activa en el gobierno supremo del Estado [HÄBERLE, P. (2003): El Estado constitucional, 1. ${ }^{a}$ reimpr., México, Instituto de Investigaciones Jurídicas, 43$].$

31 Gómez SÁNCHez, Y. (2000). Introducción al régimen constitucional español, 2. ${ }^{a}$ ed., Madrid, Sanz y Torres, 342-343. La misma expresión, «monarquía democrático-parlamentaria», es utili- 
Hasta aquí una primera aproximación a los rasgos más característicos de la monarquía sueca tal y como se diseña constitucionalmente en el Instrumento de Gobierno de 1975. Pero hay otros aspectos más específicos y también de interés que se contienen en el Capítulo 5 IG dedicado al Jefe del Estado y en la Ley de Sucesión.

Así, para que el Rey o Reina de Suecia sea el Jefe del Estado se requiere que sea ciudadano sueco y que haya alcanzado la edad de 18 años, siendo incompatible con ser ministro, Presidente de la Cámara o miembro del Parlamento (art. 2). Se prevé una Regencia interina para el caso en que el Rey no esté en condiciones de cumplir con sus obligaciones de Jefe del Estado, correspondiendo la misma al miembro de la Casa Real que deba sucederle y que esté en condiciones de asumirlas (art. 4); si el Rey muriera o abdicara y el heredero no hubiera alcanzado los 18 años o si la dinastía se extinguiera ${ }^{32}$, el Parlamento elegirá un Regente y un Vicerregente para ejercer temporalmente las funciones de Jefe del Estado (art. 5), correspondiendo la propuesta al Gobierno cuando ninguno de los mencionados esté en condiciones de ejercer las funciones, y si ninguno estuviera en condiciones la Regencia corresponderá al Presidente de la Cámara o, en su ausencia, a alguno de los Vicepresidentes, también a propuesta del Gobierno (art. 7). Si durante seis meses consecutivos el Rey hubiera estado impedido de ejercer sus obligaciones como Jefe del Estado o no hubiera podido cumplirlas, el Gobierno lo comunicará al Parlamento que decidirá si debe considerarse que el Rey ha abdicado $^{33}$ (art. 6).

zada, sin embargo, con carácter más general para referirse al conjunto de monarquías parlamentarias por De Vergottini (1983), 705 y 707-708; y Stepan, Linz y Minoves, 36.

32 Nergelius destaca que así como bajo la vigencia de la Constitución de 1809 en estos casos el Parlamento debía proceder a elegir una nueva dinastía (cabe recordar que la monarquía sueca fue electiva hasta que se convirtió en hereditaria en 1544 en el reinado de Gustavo Vasa), en la actualidad parece claro que, tras la Regencia temporal, el Parlamento tendría la opción de proclamar la República (a diferencia del caso español en el que el artículo 57.3 CE limita la discrecionalidad de las Cortes a la elección de un sucesor «en la Corona», esto es, en la Jefatura del Estado en forma monárquica). Sin embargo, en el caso sueco, a decir de este autor, en la hipótesis de extinción de la dinastía Bernardotte cabría una proclamación de la República por decisión de un Parlamento ordinario sin reformar formalmente la Constitución [Nergelius (2015), 42].

${ }_{33}$ El supuesto de que el Parlamento pueda considerar que el Rey ha abdicado en el caso de que no haya podido desempeñar sus funciones ( «has failed to perform his duties» en la traducción inglesa oficial del Parlamento sueco) plantea la cuestión de si esa imposibilidad de cumplir sus deberes podría interpretarse como una valoración política negativa acerca de su actuación —es decir, que a criterio del Parlamento no haya desempeñado adecuadamente sus funciones, en cuyo caso cabría hablar de una responsabilidad política del monarca - o se trata simplemente de una incapacidad material de llevarlas a cabo y no de un juicio de valor acerca de la gestión del Rey. 
La ley de Sucesión de 1810 originalmente excluía de la sucesión al trono a las descendientes de sexo femenino pero fue modificada en $1980^{34}$ para incluir a los descendientes de ambos sexos en línea directa descendiente, teniendo preferencia los hermanos de mayor edad y sus descendientes sobre los de menor edad y su descendencia respectiva (art. 1 de la misma), es decir, que se rige por los principios de preferencia de la línea directa y primogenitura con derecho de representación de los descendientes de quienes resulten llamados por su mayor edad.

El artículo 4 de la Ley de Sucesión obliga al Rey de Suecia a «profesar la fe evangélica pura ${ }^{35}$ » y a que los príncipes y princesas sean educadas en esa misma fe dentro del Reino y prevé la exclusión de los derechos sucesorios para los miembros de la Casa Real que no la profesen.

El matrimonio de los príncipes de la Casa Real requiere del consentimiento expreso del Gobierno a petición del Rey, perdiendo en caso contrario sus derechos a la sucesión (art. 5); el heredero al trono no puede viajar al extranjero sin conocimiento y consentimiento del monarca (art. 7) y es necesario el consentimiento del soberano y del Parlamento para que un príncipe o princesa pueda llegar a reinar en un Estado extranjero por elección, sucesión o matrimonio, en cuyo caso quedaría excluido de la sucesión al trono al igual que su descendencia (art. 8).

Finalmente, el artículo 8 del Instrumento de Gobierno declara la inmunidad del Rey y del Regente que no pueden ser perseguidos por sus acciones en calidad

34 Con respecto a esta reforma para establecer la igualdad de hombre y mujer en la sucesión al trono, ha señalado Y. Gómez Sánchez que al nacer en 1979 un segundo hijo varón (Carlos Felipe) de los actuales Reyes Carlos Gustavo y Silvia antes de entrar en vigor la reforma constitucional, los derechos sucesorios de la hija mayor y Princesa heredera, Victoria, pasaron a su hermano que fue heredero de la Corona 8 meses, hasta que, entrada en vigor la reforma en 1980, revertieron de nuevo a la Princesa Victoria [Gómez SÁnchez, Y. (2007). «La sucesión a la corona», en RoLLNERT LIERn, G. (dir.), Las monarquías europeas en el siglo XXI, Madrid, Sanz y Torres, 157].

35 Nergelius manifiesta su sorpresa porque la Comisión que elaboró la reforma de 2011 no tuviera el mandato de modificar reglas obsoletas de la monarquía como esta, que no se acomoda a las actitudes y valores de la sociedad sueca contemporánea por cuanto ello no hubiera supuesto romper el acuerdo de los partidos de no cuestionar la institución monárquica [NERGELIUS (2015): 42]. Como ocurre en las tres monarquías escandinavas confesionalmente luteranas, el monarca asume la condición de jefe de la Iglesia Nacional sueca, no por reconocimiento constitucional expreso como el caso de Noruega (arts. 2, 4 y 6 de la Constitución de Noruega) sino de forma implícita por la atribución de determinados nombramientos eclesiásticos, al igual que en Dinamarca, sin perjuicio de que el ejercicio de sus potestades efectivas, al igual que sus funciones ejecutivas se hayan desplazado bien al Gobierno, bien al Parlamento [Hurtado Martínez, J. A. (2001). «La religión en las monarquías europeas», en TORREs Del Moral, A. (dir.), Monarquía y Constitución (I), Madrid, Colex, 613-618, 606-613 y 622-623]. 
de Jefe de Estado, considerando la doctrina sueca que se trata de una inmunidad personal del Rey, no aplicable a otros miembros de la Familia real y exclusivamente penal sin que se extienda al ámbito civil ${ }^{36}$.

\section{LOS ANTECEDENTES INMEDIATOS: EL INSTRUMENTO DE GOBIERNO DE 1809}

El Instrumento de Gobierno de 1975 al que se ha hecho referencia derogó y sustituyó al anterior Instrumento de Gobierno de 1809 bajo cuya vigencia se introdujo en Suecia la monarquía parlamentaria, sin perjuicio de algunos antecedentes más remotos como el Instrumento de Gobierno de $1720^{37}$ que dio lugar a la denominada «Era de la Libertad» (1720-1772) en la que existió una forma parlamentaria de gobierno embrionaria ${ }^{38}$ que, sin embargo, fue seguida del periodo autocrático conocido como la «Era Gustaviana» (Gustavo III y Gustavo IV Adolfo) que finalizó precisamente con el Instrumento de Gobierno de 1809 y el posterior cambio de dinastía.

En 1809, en el contexto de la derrota de Suecia por Rusia y la consiguiente y traumática pérdida de Finlandia, el Rey Gustavo IV Adolfo fue destronado por un golpe de Estado protagonizado por un grupo de oficiales, produciéndose su abdicación y siendo declarado excluido de la sucesión, con sus descendientes, por el Parlamento. Poco más de tres meses más tarde y sobre la base de los trabajos de una Comisión especial, el Riksdag aprobó por unanimidad un nuevo Instrumento de Gobierno ${ }^{39}$, la Constitución de 1809 que ha estado en vigor hasta que fue reemplazada por la de 1975, siendo hasta entonces la Constitución en vigor más antigua de Europa y la segunda del mundo después de la norteamericana ${ }^{40}$. En los años siguientes se aprobaron otras tres Leyes Fundamentales:

36 Nyman (1981), 62; y Nergelius (2015), 42.

37 El primer Instrumento de Gobierno data de 1634 bajo la Regencia de la Reina Cristina [HOLMBERG y STJERNQUIST (1995), 11].

38 Petersson (2009), 3; Isberg, M. (2012). «The development of constitutional law in Sweden», introducción a THE SWEDISH RIKSDAG (2012), 15; ANDRÉN (1968), 13; y HoLMBERG y STJERNQUIST (1995), 12 y 13.

39 Sobre el proceso de elaboración del Instrumento de Gobierno de 1809, Heckscher, G. (1959). The Swedish Constitution 1809-1959. Tradition and Practice in Constitutional Development, Stockholm, The Swedish Institute, 3-6.

40 Heckscher (1959), 3; Holmberg y Stjernquist (1995), 15; Andrén (1968), 11; Elder (1970), 23; y RuIN, O. (1988). «Sweden: The New Constitution (1974) and the Tradition of Consensual Politics», en Bogdanor, V. (ed.), Constitutions in Democratic Politics, Aldershot, Gower, 309. 
- la Ley de Sucesión de 1809 (modificada en 1810, 1980 y 1994);

- la Ley del Parlamento de 1810 (la original de 1617 fue reemplazada en 1723 y sustituida después en 1866 y en 1975, perdiendo su estatus constitucional en el Instrumento de Gobierno de 1975);

— y la Ley de Libertad de Prensa de 1810 (que sustituyó a la ley del mismo nombre de 1766 , que fue la primera ley sueca con rango fundamental y fue sustituida por nuevos textos en 1812 y 1950).

Aprobada la Constitución, se eligió como nuevo monarca al tío del Rey depuesto, Carlos XIII, de 60 años de edad y sin hijos. El Parlamento eligió como sucesor a un príncipe danés pero al fallecer este accidentalmente al poco de llegar a Suecia, la nueva elección recayó en un mariscal francés del ejército de Napoleón, Jean-Baptiste Bernardotte, Príncipe de Monte-Corvo, que aceptó la oferta del Parlamento sueco convirtiéndose en el primer Rey sueco de la dinastía actualmente reinante - los Bernardotte - con el nombre de Carlos XIV Juan.

La Constitución de 1809 estableció una monarquía constitucional basada en el principio de separación de poderes, en la que el Rey ejercía el poder ejecutivo con el asesoramiento preceptivo de un Consejo de Estado ${ }^{41}$ que debía refrendar todas sus decisiones asumiendo la responsabilidad, salvo los ministros que hicieran constar en el acta del Consejo su desacuerdo ${ }^{42}$. El Rey compartía el poder legislativo con el Parlamento ${ }^{43}$ pudiendo ejercer el derecho de veto ${ }^{44}$. El poder de establecer tributos era competencia exclusiva del Parlamento quién ejercía también un poder de supervisión y control parlamentario sobre el Consejo, creándose una Comisión Constitucional con carácter permanente que tenía permiso para inspeccionar y fiscalizar las actas del Consejo ${ }^{45}$; si la misma consideraba que un ministro había aconsejado al Rey una actuación ilegal o inconstitucional podía iniciar un proceso contra el mismo o, si la actuación no fuera ilegal pero se considerara políticamente improcedente, podía exigirle al Rey el cese del

41 El artículo 4 de la Constitución de 1809 establecía: "The King alone shall govern the Realm (...) he shall, however (...) seek the information and advice of a Council of State» [ELDER (1970), 31].

42 ANDRÉn (1968), 115; y LARSSON (1991), 51-52.

43 Sin embargo, la legislación económica y administrativa era prerrogativa exclusiva del monarca [Holmberg y STJERnQuist (1995), 13; y HeCKSCHER (1959), 8].

44 "Neither the King without the approval of the Riksdag, nor the Riksdag without the consent of the King, shall have the power to make new laws or to repeal existing laws" [art. 87.1, PETERSSON (2009), 7].

45 Petersson (2009), 8; Rustow, D. A. (1955). The Politics of Compromise: A Study of Parties and Cabinet Government in Sweden, Princeton, Princeton University Press, 197 y 198; y HECKSCHER (1959), 10. 
ministro aunque este no estuviera jurídicamente obligado a cesarlo ${ }^{46}$. Se creó la figura del Ombudsman para supervisar a la Administración pudiendo iniciar procedimientos judiciales. El poder judicial se consideraba incluido en el Ejecutivo aunque los tribunales gozaban de cierta independencia ${ }^{47}$.

Sin entrar en demasiado detalle, progresivamente se fue estableciendo un sistema dualista ${ }^{48}$ en el que la libertad del Rey para nombrar a sus consejeros se veía limitada en la práctica por la necesidad de que los mismos gozasen de la confianza del Parlamento ${ }^{49}$. El régimen parlamentario monista, basado en exclusiva en la relación fiduciaria entre Parlamento y Gabinete, se introdujo en Suecia en $1918^{50}$, cuando el Rey Gustavo V, enfrentado desde 1914 con el Gobierno liberal por su política de defensa y cuya dimisión forzó, tuvo que renunciar al ejercicio de cualquier poder personal cuando tras las elecciones de 1917 aceptó nombrar un nuevo Gobierno liberal en el que por primera vez entraron los socialdemócratas que llevaban en su programa la instauración de la república, todo ello en el contexto de la introducción de la representación proporcional y del sufragio universal masculino en 1907, extendido a las dos cámaras en 1918 y a las mujeres en 1921.

Siguiendo a Petersson, lo más significativo de este proceso es que, aunque durante los siglos XIX y Xx se produjeron numerosas reformas constitucionales —en 1959 solo 13 de los 114 artículos permanecían en su redacción original aunque no se habían modificado las reglas más importantes ${ }^{51}$ — la introducción del parlamentarismo se produjo desde 1918 sin modificar formalmente el texto de $1809^{52}$, esto es, por la vía de la mutación constitucional (verfassungswandlung $^{53}$ ) atribuyendo gradualmente nuevo sentido por vía interpretativa ${ }^{54}$ a las

46 ELder (1970), 32.

47 Petersson (2009), 7; y Heckscher (1959), 9.

48 Stepan, Linz y Minoves diferencian entre la «monarquía constitucional» en la que existe un elemento de legitimidad dual desde el momento en que el Parlamento y el monarca necesitan mutuamente su apoyo para formar o cesar un gobierno y, por el contrario, la «monarquía democrático-parlamentaria» («democratic parliamentary monarchy») en la que solamente el Parlamento libremente elegido determina la formación y el cese del gobierno [STEPAN, A., LINZ, J. J. y Minoves, J. F. (2014), 36].

49 Holmberg y StJernquist (1995), 14; Hancock (1998), 446; y Heckscher (1959), 21.

50 Para una descripción de la crisis y los acontecimientos que condujeron a la adopción definitiva del sistema parlamentario en Suecia en 1918, vid. LARSSON (1991), 54-55; y RusTOw (1955), 81-85.

51 Andrén (1968), 16; y Petersson (2009), 13 y 15

52 ANDRÉn (1968), 16-17; y NyMAN (1981), 55.

53 Petersson (2009), 14.

54 Por ejemplo, las referencias al Rey en el texto de 1809 pasaron a interpretarse como si el término fuera sinónimo del Gabinete [PETERSSON (2009), 7], lo que se reconoce expresamente (y también para el Rey en Consejo) en la Disposición Transitoria 7 del Instrumento de Gobierno 
disposiciones constitucionales, sin perjuicio de algunas reformas importantes del texto escrito que son, sin embargo, la excepción ${ }^{55}$.

Para Sterzel los cambios formales de la Constitución han tenido una importancia muy limitada y un papel secundario para el desarrollo constitucional de Suecia ${ }^{56}$ y habla de un periodo de medio siglo (entre 1918 y 1968) «sin Constitución» (Constitution-less, en sueco det författningslösa balvseklet) en el que la vieja Constitución devino obsoleta y nuevos importantes principios se desarrollaron al margen de ella y sin ningún reconocimiento formal ${ }^{57}$. Petersson explica este desarrollo constitucional informal por una débil cultura constitucional ${ }^{58}$ en la que el valor normativo atribuido a la Constitución sueca en el debate público ha sido más bien escaso ${ }^{59}$ y los tribunales han sido renuentes a referirse a la Constitución, en el marco de una cultura política general en la que prima un enfoque pragmático del proceso de toma de decisiones basado en la deliberación y el consenso, en consideraciones utilitarias, la negociación y el compromiso evitando los conflictos basados en principios constitucionales abstractos. Así, afirma Petersson que en Suecia la Constitución se usa a menudo para confirmar formal-

de 1975: Rules of older law or other statute which refer to the King or the King in Council shall apply to the Government (...) unless it follows from a statute, or is otherwise apparent from the circumstances, that the reference is to the King in person, the Supreme Court, the Supreme Administrative Court, or an administrative court of appeal. Provisions which under older law or other statute shall be determined by joint decision of the King and the Riksdag shall be determined instead in an act of law».

55 En este sentido, la reforma de los Departamentos ministeriales en 1840 cuyos jefes pasaron de ser meros informadores al Consejo a auténticos ministros, las reformas de 1866-1867 sustituyendo el antiguo Parlamento de cuatro brazos por un Parlamento bicameral elegido por sufragio restringido que se reuniría anualmente, las reformas del sufragio y la introducción de la representación proporcional entre 1909 y 1921 [HOLMBERG y STJERNQUIST (1995), 14] y la introducción del referéndum consultivo o del Consejo Consultivo de Asuntos Extranjeros [Petersson (2009), 15].

${ }^{56}$ Afirma Petersson, remitiéndose a F. Sterzel, que pueden distinguirse tres periodos principales en la historia constitucional de Suecia de los siglos XIX y Xx, separados entre sí por convulsiones constitucionales: un siglo con la Constitución de 1809 (1809-1918), poco más de medio siglo de democracia en el marco formal de la antigua Constitución (1918-1968) y, finalmente, unas pocas décadas bajo la vigencia de la nueva Constitución de 1975 [Petersson (2009), 14].

57 No se ha encontrado traducción de la obra de F. Sterzel por lo que se citan sus tesis indirectamente a partir de las referencias de Petersson [Petersson (2009), 14-16].

58 Petersson (2009), 20-21.

59 Cita Petersson a G. Heckscher que en el 150 aniversario de la Constitución de 1809 en 1959 señaló que la Constitución sueca nunca ha recibido ningún reconocimiento, y mucho menos veneración, por parte de la opinión pública, no habiendo sido tratada con respeto ni por el Parlamento ni por el Gobierno, más bien al contrario, hasta el punto de que «in the public debate it had almost become ridiculous to refer to the letter and spirit of the Constitution» [PETERSSON (2009), 16]. 
mente cambios y decisiones previamente adoptadas, como el papel que envuelve («wrapping paper») las reformas políticas ya implementadas ${ }^{60}$.

En 1954 se nombró una comisión parlamentaria — la Comisión Real sobre Asuntos Constitucionales (Författningsutredningen)_- con el mandato de formular una propuesta de modernización de la Constitución que aclarase la situación jurídica en muchos ámbitos y, casi diez años después, la Comisión propuso reemplazarla por un nuevo texto constitucional por las dificultades de compatibilizar las reformas necesarias para codificar las prácticas de un sistema parlamentario monista con distribución de funciones con la redacción de 1809 basada en el principio de separación de poderes. Durante el proceso de elaboración de la nueva Constitución (1963-1974) sobre la base de los trabajos de una nueva Comisión —la Comisión Permanente sobre las Leyes Fundamentales, Grundlagberedningen-, se reformó parcialmente la Constitución en 1969 para, entre otros aspectos, reconocer formalmente el sistema parlamentario eliminando el artículo que atribuía al Rey en exclusiva el gobierno sustituyéndolo por otro que permitía al Parlamento presentar una moción de censura contra el Gabinete o individualmente contra los ministros. En este sentido puede hablarse de una continuidad constitucional porque, más allá de las diferencias formales entre los textos escritos de 1809 y 1975, desde la introducción del parlamentarismo en 1918 el sistema político ha sido esencialmente el mismo, especialmente tras la reforma parcial de $1969^{61}$.

\section{LOS PODERES DEL REY Y EL COMPROMISO DE TUREKOV}

El diseño constitucional restrictivo de las competencias del Rey en el Instrumento de Gobierno de 1975 tiene su origen en un acuerdo alcanzado previamente en 1971 entre los representantes de los partidos en la Comisión Permanente sobre las Leyes Fundamentales nombrada en 1966.

¿Por qué motivos la reforma constitucional de 1975 no se limitó a incorporar a la Constitución escrita la práctica parlamentaria seguida por la monarquía sueca bajo la vigencia de la Constitución de $1809^{62}$ y despojó al Rey de las

60 Petersson (2009), 20-22. Este autor habla de que Suecia, aunque no ha llegado a ser un sistema de common law, integraría una tercera categoría en el Derecho Comparado en la medida que ha establecido un sistema democrático de gobierno sin una Constitución escrita plenamente normativa pero sin llegar tampoco a sustituirla por un sistema de common law basado en precedentes jurisprudenciales [PETERSSON (2009), 16].

61 Petersson (2009), 17 y 20.

62 De hecho los términos de referencia de la Comisión no incluían la cuestión de la forma de Estado aunque sí incorporaban el mandato de llevar a la Constitución las reglas del gobierno parlamentario [ELDER (1970), 26]. 
competencias que hasta dicha reforma venía ejerciendo de conformidad con un Gabinete políticamente responsable ante el Parlamento? Hancock atribuye la reducción de poderes del Rey al resentimiento de los socialdemócratas por los esfuerzos desplegados por Gustavo V para influir en la política del Gobierno a favor de Alemania durante las dos guerras mundiales ${ }^{63}$. Otros autores como Bogdanor aducen el sentimiento de parte de los socialdemócratas que veían la república como una fórmula política más acorde con el igualitarismo de la sociedad sueca ${ }^{64}$.

Desde una perspectiva politológica, Bergman ha explicado muy documentadamente ${ }^{65}$ y con mucho detalle las circunstancias y razones por las que el Rey sueco perdió los poderes formales que desde 1918 habían coexistido con el funcionamiento del régimen parlamentario, poniendo el énfasis en las motivaciones de los partidos durante la discusión del texto constitucional en la nueva Comisión nombrada por el Gobierno en 1966 para sustituir a la que desde 1954 hasta 1963 había venido deliberando sobre la reforma constitucional sin haber conseguido un acuerdo aceptable ${ }^{66}$ para los cuatro partidos ${ }^{67}$ representados (Par-

${ }^{63}$ HANCOCK (1998), 45.

${ }^{64}$ Bogdanor, V. (1984). «The Government Formation Process in the Constitutional Monarchies of North-West Europe», en Kavanagh, D. y Peele, G. (eds.), Comparative Government and Politics, Boulder, Westview Press, 66-67.

${ }^{65}$ Si no se indica otra cosa, en las siguientes líneas se seguirán sus trabajos sobre esta cuestión: Bergman, T. (1992). «Multiple Goals and Constitutional Design: How the Swedish King Lost His Formal Powers», Statsvetenskaplig tidskrift, n. ${ }^{\circ}$ 95, 209-233; y Bergman, T. (1999). «Tradeoffs in Swedish constitutional design: the monarchy under challenge», en MüLlER, W. C. y STRøм, K., Policy, office, or votes: How political parties in Western Europe make hard decisions, Cambridge, Cambridge University Press, 237-257.

${ }^{66} \mathrm{El}$ informe de la Comisión dejaba a la discrecionalidad del Rey aspectos como el cese del Gabinete y la posibilidad de rechazar la presentación al Parlamento de propuestas del Gobierno y fue criticado en el entorno del Partido Social Demócrata, especialmente, por permitir al monarca rehusar la petición del Gobierno de disolver el Parlamento. En este sentido, sobre el informe de la Comisión que se publicó con el borrador de texto constitucional en 1963, vid. el comentario de Elder que señala que este informe ayudó a despertar una fuerte corriente de republicanismo en el seno del Partido Social Demócrata, especialmente entre la generación más joven: de hecho, en 1966 33 diputados socialdemócratas presentaron una moción pidiendo una comisión de estudio de la posición del Jefe de Estado en una democracia parlamentaria, incluyendo expresamente su posición en una república; la moción, después de eliminada la referencia a la república en la comisión parlamentaria correspondiente, recibió el apoyo del Primer Ministro socialdemócrata, Erlander, y fue aprobada con los votos de socialdemócratas y comunistas y con el voto en contra de conservadores, centristas y de la mayoría de los liberales [ELDER (1970), 35-41].

${ }^{67}$ Sobre los partidos políticos suecos, HANCOCK (1998), 459-469; y ANDrÉN, N. (1964). Government E politics in the Nordic countries: Denmark, Finland, Iceland, Norway, Sweden, Stockholm, Almqvist \& Wiksell, 167-172. 
tido Social Demócrata, Partido Conservador — Partido Moderado, Moderata Samlingspartiet, desde 1969—, Partido Liberal —Partido del Pueblo, Folkpartiet, desde 1934 - y Partido del Centro).

Entre los factores contextuales que favorecieron el acuerdo sobre la reforma, Bergman cita en primer lugar la discordancia obvia entre la Constitución escrita y la práctica constitucional. Por otra parte, en 1971 los socialdemócratas, con un número de escaños inferior al del bloque no socialista, gobernaban con el apoyo de la minoría comunista. Al mismo tiempo, en los tres partidos del bloque no socialista (centristas, liberales y conservadores) se había producido un cambio de líderes y se habían incrementado los esfuerzos para alcanzar una mayor cooperación; en particular el nuevo líder del Partido Moderado, Gösta Bohman, impulsó la política de cooperación intrabloque —en el que hasta entonces había desempeñado un papel secundario - como la única vía para desalojar del poder a los socialdemócratas y para ganar influencia en la política nacional. La cultura político-administrativa sueca de la época, con su énfasis en el compromiso y el consenso alcanzado a través de lentas deliberaciones en comisiones nombradas por el Gobierno, es otro elemento importante a considerar: aunque los partidos discrepaban en sus posiciones sobre la monarquía, existía consenso en que la nueva Constitución debía surgir del acuerdo entre los cuatro grandes partidos. Finalmente, en esos años coexistía la popularidad del anciano Rey Gustavo VI Adolfo con un radicalismo izquierdista favorable a reformas constitucionales de gran escala que recortasen las competencias del monarca ${ }^{68}$.

Así las cosas, en agosto de 1971 los representantes de los cuatro partidos en la Comisión alcanzaron en solo dos días un acuerdo sobre los poderes del Rey - el llamado Compromiso de Turekov (Turekovkompromissen) en atención a la ciudad en la que se celebraron las reuniones_-diseñando la posición del monarca tal y como resultó posteriormente constitucionalizada en el nuevo Instrumento de Gobierno. El Partido Social Demócrata presentó una propuesta al Partido del Centro para que fuera el Presidente del Riksdag quien propusiera al Primer Ministro (lo que había planteado este partido meses antes), aceptando también el partido centrista la ulterior exigencia socialista de que el Rey no presidiera ninguna reunión del Gobierno en la que se tomaran decisiones; sumado el Partido Liberal al acuerdo, el Compromiso fue aceptado finalmente por el Partido Moderado con la condición de que el Primer Ministro mantuviera al Rey informado de los asuntos de gobierno ${ }^{69}$.

68 Bergman, T. (1999), 238-240.

69 Bergman, T. (1999), 240-241. 
Con esta propuesta el Partido Social Demócrata resolvía el dilema al que se enfrentaba en la discusión de la reforma constitucional. Desde 1911 su posición oficial había sido favorable a la sustitución de la monarquía por la república sin que ello le hubiera impedido, sin embargo, gobernar el Reino de Suecia durante 39 años, prácticamente sin interrupción desde $1932^{70}$. Aunque la cuestión de monarquía-república no tenía interés intrínseco en sí misma por cuanto los poderes reales del Rey eran simbólicos, sí podía ser determinante de un mal resultado electoral dado el fuerte y abrumador apoyo popular a la monarquía ${ }^{71}$. Pero si proponer abiertamente la república podía suponer perder las próximas elecciones - $-\mathrm{y}$, con ello, el gobierno, que mantenía por un estrecho margen gracias al apoyo comunista - no actuar en absoluto en relación con un principio programático tendría sin duda un coste en la cohesión interna del partido, especialmente entre los intelectuales influyentes de su entorno ${ }^{72}$. En estas circunstancias, en 1969 el Congreso del Partido había aceptado la propuesta de su líder dimisionario (Tage Erlander) en virtud de la cual los socialdemócratas defenderían en la Comisión la primacía de la democracia parlamentaria estableciendo unas reglas sobre los poderes del Jefe del Estado aplicables tanto a un Rey como a un Presidente republicano; ello implicaba que el Rey no participase formalmente en las decisiones del Gobierno ni tampoco en el proceso de formación del

70 ELder (1970), 3.

71 Según Bergman, el Primer Ministro socialdemócrata —Erlander- reconoció en 1969 en la Ejecutiva Nacional del partido, en respuesta a una pregunta crítica, que una encuesta reciente había mostrado que el $80 \%$ de la juventud sueca era favorable a la continuidad de la monarquía y, por otra parte, a principios de los años 70 diversos miembros de la Comisión se refirieron a encuestas que mostraban que entre el 60 y el $80 \%$ de la población estaba a favor de la monarquía [BERGMAN (1992), 215-216]. Larsson hace referencia a una encuesta de 1978 en la que el 64\% de los encuestados preferían la monarquía como forma de la Jefatura del Estado frente a un $19 \%$ partidario de la república [LARSSON (1991), 59]. Nergelius señala que las encuestas realizadas regularmente muestran un fuerte apoyo continuado de los ciudadanos a la monarquía como institución, con un $70 \%$ regularmente en favor de la monarquía y que los argumentos favorables a la república no son percibidos como realistas; aunque la mayoría de los parlamentarios parecen ser partidarios de la república, al menos en sus declaraciones, ningún partido está persiguiendo activamente este objetivo [Nergelius (2015), 41]. Sin embargo, la Asociación Republicana afirma que una encuesta del Instituto SOM de la Universidad de Göteborg de abril de 2010 mostró que el porcentaje de los partidarios de conservar la monarquía había decrecido del 68 al $56 \%$ en solo 6 años y que dos encuestas encargadas por ellos habían confirmado la reducción del apoyo a la monarquía [REPUBLICAN Association (2011). 2010 - The beginning of the end for the Swedish monarchy. Recuperado el 26.01.2016 de http://goo.gl/7O0Q1Q].

72 Entre otras, el profesor de Ciencia Política y editor del diario matinal de mayor tirada, Herbert Tingsten, de quien afirma Bergman que, si no el primero, fue de los primeros en mencionar en 1964 la posibilidad de dejar al Presidente de la Cámara la responsabilidad de la formación del gobierno [BERGMAN (1992), 216-217]. 
mismo, buscando un acuerdo con los demás partidos para que fuera el Presidente del Riksdag quien nombrase al Primer Ministro. Y así su aceptación del Compromiso se presentó ante la opinión pública como la codificación del sistema parlamentario de gobierno ${ }^{73}$ reduciendo al mínimo posible las competencias del Rey. De esta manera, sin sufrir el desgaste electoral de proponer la República ${ }^{74}$, proponiendo la reforma de la monarquía se daba la impresión de estar avanzando hacia la república frente a críticas internas y externas ${ }^{75}$.

Con poca oposición interna e ignorando las críticas del sindicato afín, esta postura fue ratificada en el Congreso del Partido Social Demócrata de 1972 a propuesta de Olof Palme que valoró el Compromiso como un paso adelante al haber eliminado cualquier resto de poder político del otrora poderoso Rey, ahora reducido a un elemento decorativo que podía ser eliminado «de un pluma$\mathrm{zo}^{76}{ }^{7}$, afirmando que bastaría cambiar unas pocas palabras en la Constitución para que Suecia pudiera llegar a ser una república porque habían hecho una Constitución que funcionaría igualmente bien con un Presidente.

Tanto el Partido de Centro, más próximo a las tesis socialdemócratas, como el Partido Liberal, temeroso de alinearse con los conservadores frente a los otros dos partidos, no tuvieron mayor problema en aceptar el Compromiso ${ }^{77}$.

Más problemática fue la incorporación de los conservadores del Partido Moderado a este consenso que no respondía a su concepción de la monarquía. Su posición de partida era, por un lado, mantener la participación del Rey en las funciones estatales, al igual que otros Jefes de Estado, para asegurar su rol de símbolo de la unidad nacional, entendiendo ello compatible con la democracia parlamentaria y, por otro, aparecer ante la opinión pública como los defensores de la monarquía frente al ataque socialdemócrata, lo que podía beneficiarles en la campaña electoral de las próximas elecciones de 1973.

La voluntad de evitar la división dentro del bloque no socialista evidenciando en un contexto preelectoral que no eran capaces de ponerse de acuerdo en un asunto tan importante se ha señalado como la razón principal de que los conser-

73 La tarea principal de la Comisión en lo que se refiere a la monarquía se definía en los términos de referencia como «codificación y aclaración» excluyendo cualquier cambio en la forma monárquica del Estado [ELDER (1970), 35].

${ }_{74}$ De hecho, en la presentación del proyecto de nueva Constitución al Parlamento en 1973 el Gobierno socialdemócrata declaró que la preservación de la monarquía era un presupuesto, un punto de partida para que la formulación de una nueva Constitución pudiera ganar el apoyo necesario del Parlamento y de la opinión pública [NyMAN (1980), 62].

75 Bergman, T. (1999), 241-244.

76 Bergman, T. (1992), 224-225.

77 Bergman, T. (1999), 244. 
vadores aceptaran el Compromiso para no dificultar una posible victoria electoral del bloque burgués. Es menos probable que consideraran que existía un peligro real de que el Partido Social Demócrata cambiara su posición y propusiera una república cuando ya había llegado a un acuerdo con centristas y liberales y era conocido el fuerte apoyo popular a la monarquía. Señala Bergman que ha habido, sin embargo, cierta controversia acerca de si la aceptación del Compromiso por el Partido Moderado fue una decisión personal de su representante en la Comisión (Hernelius) que no se ajustó a las instrucciones de la dirección del partido, cuyo líder llegó a afirmar en rueda de prensa, poco antes de la reunión de Turekov, que estaban dispuestos a dar la batalla para que los socialdemócratas no aboliesen la monarquía sin que nadie lo advirtiera. Con independencia de ello, lo cierto es que la dirección del Partido respaldó a su representante en la Comisión y aceptó el Compromiso evitando desautorizarlo en aras de la cohesión interna y de mantener una posición conjunta de los tres socios de la coalición antisocialista sobre el diseño constitucional ${ }^{78}$.

Así, después del Compromiso, el Partido Moderado se presentó como el garante de la continuidad de la monarquía que había forzado a los socialdemócratas a mantenerla y a aceptar que el Rey continuara ejerciendo algunas funciones ceremoniales. En el Congreso del Partido, sin embargo, se debatió intensamente si debían distanciarse del Compromiso aunque su líder, Bohman, logró finalmente el respaldo alegando que la continuidad de la monarquía sueca quedaba asegurada en el Compromiso mientras que reabrir el debate podría llevar a un peor resultado y la retirada del mismo sería aprovechada por los socialdemócratas para acusarles de falta de credibilidad y de coherencia interna. Sin embargo, el Congreso acordó que dentro del marco del Compromiso se intentara avanzar al máximo hacia la postura inicial del partido y, de hecho, en las reuniones posteriores para concretar la propuesta los conservadores obtuvieron concesiones como mantener la inmunidad del monarca y que conservara el mando supremo de las Fuerzas Armadas, aún sin poder formal.

En el debate final en el Riksdag, parlamentarios conservadores adujeron que la estrategia socialdemócrata de concebir la nueva Constitución como un paso en el camino hacia la república quedaba demostrada por el hecho de que las palabras «Rey»y «Monarca» habían sido prácticamente eliminadas utilizándose en su lugar el término «Jefe del Estado»; pese a ello, solo un conservador votó en contra, dos se abstuvieron y el resto votaron a favor ${ }^{79}$.

78 Bergman (1992), 215 y 218-223; y Bergman (1999), 244-248.

79 Bergman (1999), 248-249. Concluye este autor señalando semejanzas entre las estrategias elegidas por el Partido Social Demócrata y el Partido Moderado. Ante un conflicto entre sus 


\section{DEL PARLAMENTARISMO NEGATIVO AL VOTO OBLIGATORIO DE INVESTIDURA EN LA REFORMA DE 2011}

La exclusión del monarca sueco del proceso de formación del Gabinete en el Instrumento de Gobierno de 1975 es sin duda el aspecto más significativo de la nueva posición del Jefe de Estado por cuanto supone una excepción en las democracias parlamentarias europeas, tanto monárquicas como republicanas ${ }^{80}$.

El Instrumento de Gobierno de 1975 (art. 2, Cap. 6 y nuevo artículo 4 tras la reforma de 2011) establece que cuando tenga que ser nombrado un nuevo Primer Ministro, el Presidente del Riksdag, después de consultar con los representantes de los grupos parlamentarios, presentará una propuesta que será votada en los cuatro días siguientes y la misma quedará aprobada si no votan en contra más de la mitad de los parlamentarios. Se trata de una variante inusual del denominado «parlamentarismo negativo ${ }^{81}{ }$, vigente en Escandinavia (salvo en Finlandia ${ }^{82}$ y en la mayoría de las monarquías europeas ${ }^{83}$ — con las excep-

diversos objetivos, ambos optaron por transigir con un compromiso que les permitía mantener la cohesión interna y postergaba sus fines políticos programáticos — respectivamente, la república y una monarquía con poderes simbólicos- en beneficio de otros objetivos: los socialdemócratas, evitar la pérdida de votos y conservar el poder, lo que les permitiría implementar otras políticas de mayor valor intrínseco; y los conservadores, mantener la unidad del bloque no socialista como medio para que la coalición tripartita alcanzase el poder en las próximas elecciones, aún a costa de no obtener un rédito electoral inmediato. De hecho en las siguientes elecciones de 1973, los dos bloques obtuvieron el mismo número de escaños gobernando los socialdemócratas en minoría, y las elecciones de 1976 dieron lugar a un gobierno de los tres partidos del bloque burgués quedando fuera del gobierno los socialdemócratas por primera vez en más de cuarenta años [BERGMAN (1992), 226-227].

80 Señala Colliard que Suecia e Irlanda son los únicos sistemas parlamentarios —y, fuera del ámbito europeo, Japón - en los que el Parlamento designa al Primer Ministro sin intervención previa del Jefe del Estado; pero así como en Irlanda y Japón, el Jefe del Estado nombra Primer Ministro a posteriori al designado previamente por el Parlamento, Suecia es el único caso en el que el nombramiento no lo lleva a cabo el Jefe del Estado sino el Presidente del Riksdag [Colliard, J. C. (1981). Los regimenes parlamentarios contemporáneos, Barcelona, Blume, 59-60].

${ }^{81}$ Fusilier, R. (1960). Les monarchies parlamentaires: ètude sur les systèmes de gowvernement (Suède, Norvège, Danemark, Belgique, Pays-Bas, Luxembourg), Paris, Les Éditions Ouvrières, 227; SÁNCHEZ Agesta, L. (1973). Curso de Derecho Constitucional Comparado, 5. ${ }^{a}$ ed., Madrid, Universidad de Madrid, Facultad de Derecho, Sección de Publicaciones, 153-155; Colliard (1981), 58 y 60; Nyman (1981), 63; Duranti (2012), 3-4; y Nergelius, J. (2013). «Constitutional reform in Sweden. Some important remarks», Tijdschrift voor Constitutioneel Recht, fasc. 4, 372-374.

82 Duranti (2009), 81 y 90.

83 Bogdanor (1984), 55-57; y Colliard (1981), 57-61. 
ciones de Bélgica ${ }^{84}$, España y, desde 2012, los Países Bajos ${ }^{85}$ —, —, que implica que el Primer Ministro empieza a ejercer sus funciones desde que el Rey lo nombra sin una votación parlamentaria previa en la que se le otorgue expresamente la confianza; dicha confianza se presume y se mantiene en el cargo en tanto no se apruebe contra él una moción de censura, facilitándose así la formación de gobiernos minoritarios ${ }^{86}$. La particularidad del caso sueco es que, aunque se requiere una votación previa al nombramiento del Primer Ministro, dicha votación no es en realidad de investidura o de confianza sino de «no censura» o «no desconfianza» por cuanto lo relevante no son los votos favorables que obtenga el candidato sino que los votos contrarios no alcancen la mayoría absoluta de la Cámara.

Para Bogdanor, aunque no fue el objetivo de la reforma de 1975, este sistema, que transfiere al Presidente de la Cámara el protagonismo en la propuesta de Primer Ministro, ha servido para proteger al Rey de verse comprometido políticamente por su participación en la formación del gobierno, riesgo este inherente al parlamentarismo negativo en el que el soberano, a la hora de proponer uno u otro candidato, no solo debe valorar que no suscite tal rechazo del Parlamento que pueda dar lugar a la presentación de una moción de censura sino también si debe ser alguien capaz de obtener positivamente el apoyo de la mayo-

${ }^{84}$ En el caso de Bélgica, el voto de confianza no se menciona en la Constitución pero por convención constitucional el Primer Ministro del nuevo Gobierno expone su programa ante ambas cámaras y debe obtener la aprobación de la mayoría de cada una de ellas [BoGDANOR (1984), 5].

85 MolinA, I. (2016). «The king reigns but be does not rule»: monarquías parlamentarias y formación del gobierno», Agenda Pública, 7 de marzo de 2016. Recuperado el 21.11.2016 de https://goo.gl/kYtzw2.

86 Bogdanor (1984), 55-56. Nergelius ha señalado que el principio del parlamentarismo negativo ha permitido en Suecia gobiernos débiles carentes del apoyo de una mayoría parlamentaria desde el momento en que sería suficiente con que un único parlamentario (de un total de 349) - o incluso ninguno — votara a favor del candidato propuesto para que el mismo resultara nombrado Primer Ministro siempre que no votaran en su contra más de 174 parlamentarios y recuerda que esta posibilidad no es del todo teórica por cuanto en 1978 la líder liberal Ola Ullsten fue elegida Primer Ministro solo con los 38 votos de su propio partido, al abstenerse los socialdemócratas y votar en su contra 55 conservadores y 17 comunistas [NERGELIUS (2013), 372, 374 y nota 9; vid. también BogDANOR (1984), 56]. Sobre la correlación entre parlamentarismo negativo y gobiernos minoritarios desde una perspectiva empírica y la opción en la reforma constitucional sueca de 1975 por este tipo de parlamentarismo en combinación con una votación previa por mayoría absoluta, vid. BERGMAN, T. (1993). «Constitutional design and government formation: The expected consequences of negative parliamentarism». Scandinavian Political Studies, vol. 16, n. ${ }^{\circ} 4,285-304$. 
ría o basta con que pueda formar un gobierno minoritario tolerado por el resto de las fuerzas parlamentarias ${ }^{87}$.

Sin embargo, la crítica que hace a este procedimiento es que si el mismo fue diseñado para evitar que unos supuestos prejuicios ideológicos del Rey perjudicaran la formación de gobiernos de izquierda, los constituyentes no se cuestionaron si el Presidente de la Cámara podría tener mayor inclinación que el Rey a manipular el proceso de formación del gobierno ni valoraron los peligros de una posible politización del Presidente. En apoyo de esta crítica, Bogdanor relata varios episodios a su juicio reveladores de la facilidad con que el Presidente del Parlamento puede actuar de forma partidista ${ }^{88}$ y advierte del riesgo de que los partidos no propongan para la Presidencia de la Cámara candidatos respetados que permanezcan al margen de la contienda política sino hábiles partisanos que puedan aprovechar su posición institucional para maniobrar de forma partidista en la batalla por el nombramiento de Primer Ministro, habida cuenta de que el Instrumento de Gobierno solo regula los aspectos formales y menos polémicos del proceso de formación del gobierno.

Concluye Bogdanor que, además del riesgo de politización del Presidente, hay mucho más peligro de que este haga un mal uso de su poder de que lo haga el Rey desde el momento en que el primero será un antiguo político de partido mientras que un monarca constitucional no se habrá identificado con ningún partido y no tendrá la tentación de actuar por móviles partidistas; más aún, es

87 BOGDANOR (1984), 56-57

88 En este sentido, refiere que, aunque no está documentado con precisión, después de las elecciones de 1979 y ante las dificultades del líder del Partido del Centro, Thorbjörn FaIldin, para formar una coalición de los tres partidos burgueses, el Presidente del Riksdag, socialdemócrata, le amenazó con llamar a Olof Palme, el líder del Partido Social Demócrata, si no procedía con rapidez, lo que hubiera supuesto la identificación pública del Presidente con una posición partidista en el proceso de formación de gobierno y la imposibilidad de desempeñar eficazmente sus funciones al perder el respeto de uno de los bloques parlamentarios. Explica también la ocasión que en 1981 tuvo el Presidente del Parlamento sueco para manipular el proceso de formación del gobierno al abandonar el Partido Moderado la coalición gobernante de los tres partidos burgueses por disconformidad con el proyecto de reforma fiscal; al tener que iniciar el proceso de nombramiento de un nuevo gobierno - lo que sucede en Suecia por convención constitucional siempre que algún partido sale de la coalición gobernante- y puesto que los partidos burgueses solo tenían un voto más que los socialistas y comunistas en el Riksdag, el Presidente podría haber defendido la decisión de llamar a formar gobierno al socialdemócrata Palme con el argumento de que, al haberse enfrentado los moderados con los otros dos partidos burgueses, el bloque socialista se había convertido en el mayoritario; finalmente, no lo hizo y le pidió al líder del Partido del Centro (Falldin) que siguiera al frente de un gobierno de coalición con el Partido del Pueblo (liberal), pero el margen para la discusión y la polémica pudo haber sido claramente muy amplio en tales circunstancias [BOGDANOR (1984), 68-69 y 67]. 
muy probable que el monarca haya tenido una experiencia política más dilatada y continuada y conozca las posiciones de los partidos a través de sus consejeros personales desde su madurez política. El Rey habrá sido formado desde sus primeros años para la responsabilidad de formar gobierno, a diferencia del Presidente, y solo estará interesado en la imparcialidad. Por esta razón, entiende que la Constitución sueca no ofrece una solución especialmente buena para el problema de la formación de gobierno en una monarquía constitucional por cuanto es probable que cause problemas mayores que el que pretende resolver. A su juicio, es siempre inevitable un cierto grado de discrecionalidad del monarca en el proceso de formación del gobierno en sistemas multipartidistas, más allá del marco normativo e institucional y de las convenciones que puedan haberse desarrollado; la solución sueca revela que el desacuerdo entre las fuerzas políticas acerca del rol del soberano en este proceso hizo intolerable la discrecionalidad del monarca para optar entre propuestas alternativas y transferir este poder al Presidente fue una de las principales razones para reformar el Instrumento de Gobierno en $1975^{89}$.

El 1 de enero de 2011 entró en vigor una reforma del Instrumento de Gobierno que modificó la regulación del procedimiento de nombramiento del Primer Ministro en el que, como se ha visto, el Rey no toma parte y todo el protagonismo corresponde al Presidente de la Cámara ${ }^{90}$. De acuerdo con el nue-

89 BOGDANOR (1984), 66-70.

90 La ausencia del Rey sueco en el proceso de formación del Gobierno y el protagonismo exclusivo del Presidente del Riksdag contrasta con el procedimiento de investidura del Presidente de Gobierno en España en el que corresponden al Rey tanto la propuesta de candidato como el nombramiento del mismo si resulta investido [arts. 62. d), 99.1 y 3 CE], actuando en ambas ocasiones con el refrendo del Presidente del Congreso de los Diputados (art. 62.1 CE) cuyo papel constitucional se limita a mediar en el proceso de consultas con los representantes de los grupos políticos con representación parlamentaria, a trasladar la propuesta regia de candidato al Congreso, a comunicar el resultado de la votación de investidura al Rey (art. 171.6 del Reglamento del Congreso de los Diputados) y, en su caso, a someter a la firma del Rey el Decreto de disolución de las Cortes Generales y de convocatoria de elecciones si transcurrieran dos meses a partir de la primera votación de investidura sin que ningún candidato propuesto hubiere obtenido la confianza del Congreso (art. 99.5 CE y 172.2 del Reglamento del Congreso de los Diputados), tal y como han puesto de manifiesto los dos últimos procesos de investidura tras las elecciones de 20 de diciembre de 2015 y 26 de junio de 2016.

La discrecionalidad del Rey para proponer el candidato y el significado del refrendo de dicha propuesta por el Presidente del Congreso de los Diputados — certificante de la mera legalidad formal de la propuesta o, por el contrario, límite material mediante el que el Presidente garantizaría la oportunidad política de la misma - ha sido una cuestión debatida doctrinalmente desde que el régimen constitucional comenzó su andadura [en este sentido, Torres Muro, I. (1995). «El refrendo de la propuesta real de candidato a la Presidencia del Gobierno», Revista de Estudios 
vo artículo 3 del Cap. 6, no más tarde de dos semanas después de que se reúna, el nuevo Parlamento electo determinará mediante una votación si el Primer Ministro tiene suficiente apoyo en el Parlamento; si más de la mitad de los parlamentarios votan en contra, el Primer Ministro será cesado.

La clave de esta reforma reside en que tanto la redacción anterior de la Constitución como la nueva redacción de 2011 no prevén el cese del Primer Ministro tras la celebración de elecciones de tal manera que, antes de la reforma, el Primer Ministro podía sencillamente permanecer en el cargo tras las elecciones sin someterse a votación; y ello por cuanto la votación solo venía exigida cuando tuviera que nombrarse un Primer Ministro (art. 2, Cap. 6, anterior a la reforma), esto es, en los casos de cese del mismo por la aprobación de una moción de censura o por fallecimiento ${ }^{91}$. La modificación de 2011 mantiene la regla de someter a votación la propuesta de Primer Ministro formulada por el Presidente del Parlamento cuando tenga que ser nombrado un Primer Ministro (art. 4, Cap. 6, en el texto de 2011), pero añade una disposición (el mencionado nuevo art. 3 del Cap. 6) que exige que, en todo caso, el nuevo Parlamento resultante de unas elecciones, en las dos semanas siguientes a su constitución, vote si apoya o no al Primer Ministro.

Por lo tanto, la novedad introducida en 2011 es que, tras la celebración de elecciones, el Primer Ministro debe someterse a un voto obligatorio de investidura, aunque se mantiene en lo esencial el principio del parlamentarismo negativo en la medida que podrá continuar en el cargo si no votan en su contra 175 o más diputados, con independencia de los votos favorables que recabe ${ }^{92}$.

Políticos, (88), 150-154 y 159-163; y «Refrendo y monarquía», Revista Española de Derecho Constitucional, 29 (87), 55-56] pero lo cierto es que en las dos últimas investiduras, en las que la fragmentación parlamentaria descartó el automatismo de proponer al candidato de la fuerza más votada, los Presidentes del Congreso de los Diputados no han adoptado un papel activo en el proceso de investidura — como puso de manifiesto críticamente BAR Cendón, A. (2016). «El Rey, las elecciones y la Constitución», en Las Provincias, 29 de mayo de 2016 — de tal manera que en modo alguno puede considerarse que su voluntad haya sido la decisoria en la formulación de la propuesta. Así pues, no parece que pueda decirse que la práctica constitucional española haya aproximado el modelo español al modelo sueco por la vía de considerar que es el Presidente del Congreso de los Diputados quien, por el hecho de refrendar la actuación del Rey, ejerce materialmente la facultad de proponer el candidato a Presidente de Gobierno.

${ }_{91}$ Arts. 5 y 7 del Cap. 6 en la redacción de 1975 que pasan a ser los artículos 7 y 9 del mismo Capítulo en la redacción de 2011.

92 Nergelius (2013), 374; Duranti (2012), 3-4; y Bianchi, P. (2014). «Gli ordinamenti scandinavi», en Carrozza, A. Di Giovine y G. F. Ferrari, Diritto costituzionale comparato, t. I, Roma, Laterza, Roma, 330. 
Title:

The singularities of the Swedish monarchy in the European framework: The King as a static symbol of the State.

\section{Summary:}

I. Approach to the topic. II. General characterization of the Swedish monarchy in the Instrument of Government of 1975. III. The immediate antecedents: the Instrument of Government of 1809. IV. The King's Powers and the Compromise in Turekov. V. From the negative parliamentarianism to the mandatory vote of confidence in the reform of 2011.

\section{Resumen:}

En el marco de las monarquías parlamentarias europeas, la configuración constitucional de la monarquía sueca contemporánea presenta singularidades que merecen atención.

Se parte de una visión panorámica general de la monarquía sueca en el Instrumento de Gobierno de 1975 que desvincula la Jefatura del Estado de los poderes estatales estableciendo así un modelo propio de racionalización de la monarquía parlamentaria en el texto constitucional escrito y se analiza la significativa carencia de competencias que individualiza la posición del Jefe de Estado sueco respecto de los restantes soberanos europeos.

Se aborda a continuación la evolución de la institución en Suecia a partir del anterior Instrumento de Gobierno de 1809 que estableció una monarquía constitucional basada en el principio de separación de poderes. Progresivamente se fue introduciendo el parlamentarismo desde 1918 sin modificar formalmente el texto constitucional, atribuyendo nuevo sentido por vía interpretativa a las disposiciones constitucionales. Fue en 1969 cuando mediante una reforma parcial de la Constitución se incorporó formalmente el sistema parlamentario al reconocerse al Parlamento la posibilidad de presentar una moción de censura.

Se trata después la discusión sobre los poderes del Rey durante la tramitación parlamentaria de la nueva Constitución de 1975 que culminó con el denominado Compromiso de Turekov de 1971 en el que los partidos políticos suecos consensuaron finalmente un diseño constitucional restrictivo de las competencias del Rey, atendiendo a las circunstancias y razones por las que el monarca sueco perdió los poderes formales que desde 1918 habían coexistido con el funcionamiento del régimen parlamentario, poniendo el énfasis en las moti- 
vaciones de los partidos representados en la Comisión que redactó el nuevo Instrumento de Gobierno.

El trabajo finaliza haciendo referencia a la llamativa exclusión del Jefe de Estado sueco del proceso de formación del Gabinete en el Instrumento de Gobierno de 1975 y a la variante inusual del parlamentarismo negativo adoptada por cuanto la votación previa al nombramiento del Primer Ministro no es en realidad de confianza sino de «no censura» o «no desconfianza». Con la reforma constitucional de 2011 se introdujo la novedad de que, tras la celebración de elecciones, el Primer Ministro debe someterse a un voto obligatorio de investidura, aunque se mantiene en lo esencial el principio del parlamentarismo negativo en la medida que podrá continuar en el cargo si no votan en su contra más de la mitad de los diputados, con independencia de los votos favorables que recabe.

\section{Abstract:}

Within the framework of the European parliamentary monarchies, the constitutional design of the contemporary Swedish monarchy has some singularities worthy of attention.

The paper starts from a panoramic overview of the Swedish monarchy in the Instrument of Government of 1975 that dissociates the Head of State from the state powers thus setting up a characteristic model of rationalization of the parliamentary monarchy in the written constitutional text and analyzes the significant lack of powers that individualizes the position of the Swedish Head of State compared with the rest of the European sovereigns.

To continue, the evolution of the institution in Sweden from the previous Instrument of Government of 1809, that established a constitutional monarchy based on the principle of separation of powers, is considered. Parliamentarism was progressively introduced from 1918 without formally amending the constitutional text, giving new sense to the constitutional dispositions by means of interpretation. It was in 1969 that, through a partial reform of the Constitution, the parliamentary system was formally incorporated when Parliament was granted the possibility of bringing a vote of no confidence.

Then, it goes on with the discussion about the King's powers in the travaux préparatoires of the new Constitution of 1975 that culminated with the so-called Compromise in Turekov in 1971 in which the Swedish political parties finally agreed on a constitutional design restricting the King's powers, paying attention to the circumstances and reasons that explain why the Swedish monarch lost the formal powers that had coexisted since 1918 with the functioning of the 
parliamentary system, emphasizing the motivations of the parties represented in the Commission that drafted the new Instrument of Government.

The paper concludes by referring to the striking exclusion of the Swedish Head of State from the Cabinet formation process in the Government Instrument of 1975 and the unusual variant of negative parliamentarism adopted in which the vote of the Prime Minister previous to his appointment is not really a vote of confidence but of «no no-confidence». With the constitutional reform of 2011, the novelty introduced was that, following the elections, the Prime Minister must undergo a mandatory vote of confidence, although the principle of negative parliamentarism is maintained essentially as long as he can continue in office if more than half of the members of Parliament do not vote against him, irrespective of the favorable votes he receives.

Palabras clave:

Suecia - Jefatura del Estado - Monarquía parlamentaria - Parlamentarismo negativo.

Key words:

Sweden - Head of State - Parliamentary monarchy - Negative parliamentarism. 